\title{
Management of new-onset mitral regurgitation with intraoperative angiography and intraoperative percutaneous coronary intervention
}

\author{
James P. Greelish, MD, ${ }^{a}$ Susan S. Eagle, MD, ${ }^{c}$ David X. Zhao, MD, ${ }^{b}$ Robert J. Deegan, MD, ${ }^{c}$ Marshall H. Crenshaw, MD, \\ Jorge M. Balaguer, MD, ${ }^{a}$ Rashid M. Ahmad, MD, and John G. Byrne, MD, ${ }^{a}$ Nashville, Tenn
}

$\mathrm{N}$ ew-onset mitral regurgitation after routine coronary revascularization is most often the result of ischemia and may be secondary to acute graft dysfunction. After securing the diagnosis, the surgeon must speculate as to the cause (eg, myocardial stunning, subendocardial ischemia, poor myocardial protection, or thrombosis, kinking, or anastomotic obstruction of the graft). Currently available intraoperative diagnostic tools include transesophageal echocardiography, flow meters, and manual palpation of grafts, all of which are limited. Surgical graft revision invariably requires a second period of cardiopulmonary bypass and aortic crossclamping. We describe a patient in whom newonset severe mitral regurgitation was diagnosed by intraoperative echocardiography in our new "hybrid" operating suite. In this environment, a combined catheterization laboratory and operating room, and the use of intraoperative completion angiography, crystallized the cause of our patient's mitral regurgitation and provided a rapid solution to the problem without the need for another period of cardiopulmonary bypass or aortic clamping.

\section{Clinical Summary}

A 76-year-old man was referred for coronary artery bypass grafting. He had a history of myocardial infarction 5 months before surgery, for which he underwent percutaneous coronary intervention to the left anterior descending artery. He recovered well, but later presented with anginal symptoms, severe 3-vessel disease, and in-stent restenosis. Preoperative transthoracic and transesophageal echocardiography documented trace mitral regurgitation. The patient underwent uneventful coronary artery bypass grafting of the left internal thoracic artery to left anterior descending artery, saphenous vein to diagonal artery, and saphenous vein to obtuse marginal artery. Intraoperative conventional biplanar completion angiography demonstrated patent grafts to the diagonal and left anterior descending arteries. However, the obtuse marginal vein graft had an eccentric $70 \%$ stenosis in the midthird and a valve distally that produced a $60 \%$ diameter stenosis (Figure 1). Contemporaneously, intraoperative transesophageal echocardiography

\footnotetext{
From the Department of Cardiac Surgery, ${ }^{\mathrm{a}}$ Cardiovascular Division, ${ }^{\mathrm{b}}$ and Department of Anesthesia, ${ }^{\mathrm{c}}$ Vanderbilt University Medical Center, Nashville, Tenn.

Received for publication Aug 29, 2005; accepted for publication Aug 31, 2005.

Address for reprints: John G. Byrne, MD, Department of Cardiac Surgery, Vanderbilt University Medical Center, 2311 Pierce Ave, Room 2400, Nashville, TN 37232-8815 (E-mail: john.byrne@ vanderbilt.edu).

J Thorac Cardiovasc Surg 2006;131:239-40

$0022-5223 / \$ 32.00$

Copyright $\odot 2006$ by The American Association for Thoracic Surgery

doi:10.1016/j.jtcvs.2005.08.063
}

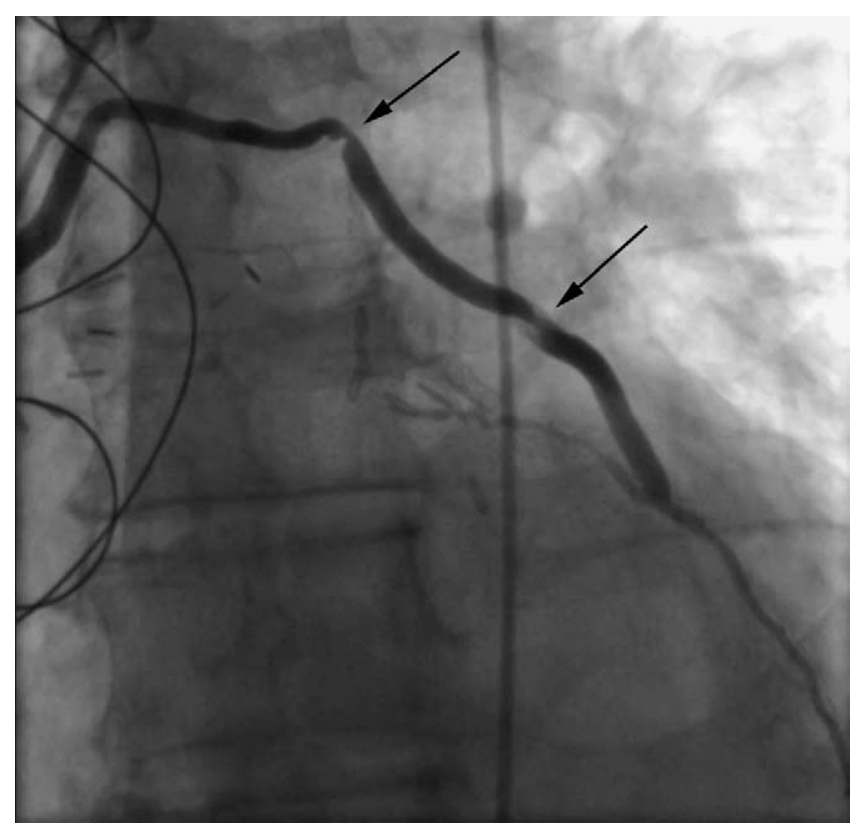

Figure 1. Intra-operative completion angiogram demonstrating 2 obtuse marginal saphenous graft lesions caused by a kink at a hemoclip and a vein valve (arrows).

demonstrated new-onset severe mitral regurgitation with pulmonary vein flow reversal. This was thought to be the result of regional/papillary muscle ischemia from the obtuse marginal vein graft dysfunction. However, visual graft inspection revealed no obvious abnormality. While the patient was in the hybrid suite, with the chest open, drug-eluting stents were deployed at each graft lesion leaving a $0 \%$ residual stenosis and Thrombolysis in Myocardial Infarction III flow, with recruitment of additional collaterals on the lateral wall (Figure 2). Immediately after this, transesophageal echocardiography showed complete resolution of the mitral regurgitation and normalization of pulmonary vein flow.

The "hybrid" approach has recently been shown to reduce mortality associated with complex cardiac procedures. ${ }^{1}$ These results have prompted the creation of hybrid operating rooms in which routine intraoperative completion angiograms can be performed for quality assurance. Our patient exemplifies the need for, and value of, "sighted" surgery through the use of postprocedure imaging. In the hybrid operating room, immediate intraoperative completion angiography allows critical assessment of graft patency, including both conduit characteristics and anastomotic quality. Intraoperative correction of these lesions may aid in avoiding early graft failure, which is currently reported at $15 \%$ at 1 year. ${ }^{2}$ 


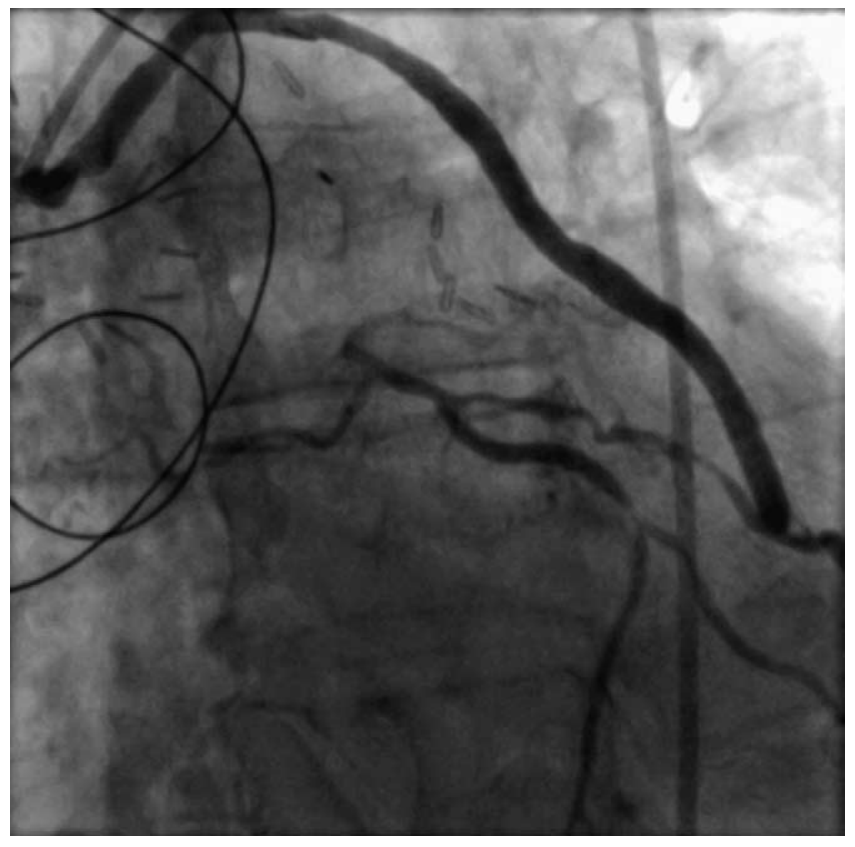

Figure 2. Intra-operative completion angiogram after percutaneous intervention with improved runoff in recruited collaterals.
A second unique advantage of the hybrid operating environment is in providing less-invasive therapeutic options. As in our patient, surgical graft revision would have required a second period of cardiopulmonary bypass and aortic clamping, and this was avoided by electing to perform a less-invasive percutaneous intervention. This resulted in a dramatic improvement in the graft flow and distal runoff with recruitment of collaterals and immediate resolution of the patient's mitral regurgitation. Moreover, the hybrid environment will undoubtedly lead to more liberal use of minimally invasive valve operations combined with percutaneous coronary interventions and combined surgical and percutaneous revascularization techniques. ${ }^{3}$

\section{References}

1. Byrne JG, Leacche M, Unic D, Rawn JD, Simon DI, Rogers CD, et al. Staged initial percutaneous coronary intervention followed by valve surgery ("hybrid approach") for patients with complex coronary and valve disease. J Am Coll Cardiol. 2005;45:14-8.

2. Goldman S, Zadina K, Moritiz T, Ovitt T, Sethi G, Copeland JG, et al. Long-term patency of saphenous vein and internal mammary artery grafts after coronary artery bypass surgery. $J$ Am Coll Cardiol. 2004; 44:2149-56.

3. Stahl K, Boyd WD, Vassiliades TA, Karamanoukian HL. Hybrid robotic coronary artery surgery and angioplasty in multivessel coronary artery disease. Ann Thorac Surg. 2002;74:S1358-62.

\title{
Aortobronchial fistula after aortic coartactation
}

\author{
Alfonso L. Quintana, MD, PhD, Esther Martínez Aguilar, MD, Alvaro Fernandez Heredero, MD, Vicente Riambau, MD, \\ Laura Paul, MD, and Francisco Acín, MD, PhD, Madrid, Spain
}

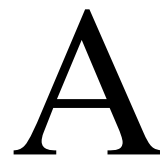

ortobronchial fistulas are an uncommon, but potentially fatal, complication of reconstructive surgery in the thoracic aorta.

Endovascular treatment is a less-invasive technique and represents an alternative for the treatment of this disease, particularly when conditions are inadequate for open surgery. We

\footnotetext{
From the Department of Angiology and Vascular Surgery, Getafe University Hospital, Madrid, Spain.

Received for publication July 3, 2005; revisions received Sept 30, 2005; accepted for publication Oct 7, 2005.

Address for reprints: Alfonso Lopez Quintana, MD, Department of Angiology and Vascular Surgery, Getafe University Hospital, Road Toledo 12,5 Km, Getafe, Madrid 28905, Spain (E-mail: esthermartinezaguilar@ hotmail.com).

J Thorac Cardiovasc Surg 2006;131:240-3

$0022-5223 / \$ 32.00$

Copyright $\odot 2006$ by The American Association for Thoracic Surgery doi:10.1016/j.jtcvs.2005.10.005
}

report a case of an aortobronchial fistula occurring 15 years after surgery for aortic coarctation that was resolved by use of endovascular treatment.

\section{Clinical Summary}

A 47-year-old man was transferred to our department because of an episode of massive hemoptysis not requiring recovery measures. The patient had undergone surgery for an aortic coarctation 15 years before. In the last year, he had had several minor episodes of hemoptysis for which he was being monitored by the pneumology department.

An initial bronchoscopic examination showed glandular openings that filled with blood in the medial wall of the right main bronchus and a slow sheet bleeding from both left lobes. The chest computed tomographic (CT) report suggested an aortobronchial fistula (Figure 1, A), and this diagnosis was confirmed by angiomagnetic resonance imaging.

The patient underwent surgery with general anesthesia and systemic heparinization. A left femoral approach and a $5 \mathrm{~F}$ inserter were used for arteriography, which showed a dilated 